REVISTA DE ESTUDOS EM ARTES CÊNICAS

E-ISSN 2358.6958

\title{
Ensino remoto de dança na Escola Livre de Dança da Maré em 2020 durante a pandemia de COVID-19
}

Gabriel Ramon Ferreira Lima

\section{Para citar este artigo:}

LIMA, Gabriel Ramon Ferreira. Ensino remoto de dança na Escola Livre de Dança da Maré em 2020 durante a pandemia de COVID-19. Urdimento - Revista de Estudos em Artes Cênicas, Florianópolis, v. 3, n. 42, dez. 2021.

do) DOI: http:/dx.doi.org/10.5965/1414573103422021e0113

Este artigo passou pelo Plagiarism Detection Software| iThenticate 


\title{
Ensino remoto de dança na Escola Livre de Dança da Maré em 2020 durante a pandemia de COVID-191
}

\author{
Gabriel Ramon Ferreira Lima²
}

\begin{abstract}
Resumo
Este artigo buscou registrar e refletir sobre experiências de ensino remoto de dança desenvolvidas durante a pandemia da COVID-19, na cidade do Rio de Janeiro, em 2020, pela Escola Livre de Dança da Maré. Atuando com educação não-formal em dança, através de estratégias síncronas e assíncronas de ensino, a Escola continuou a alcançar suas/seus alunas/os durante o isolamento social imposto pela pandemia do novo coronavírus. Num contexto em que as desigualdades sociais ficaram ainda mais evidentes para quem precisou conectar-se à internet e usar aparelhos eletrônicos para estudar em casa, este artigo refletiu sobre como a realidade do bairro Maré não colaborou para o melhor acontecimento das aulas online da Escola Livre de Dança da Maré.
\end{abstract}

Palavras-chave: Dança. Educação não-formal. Ensino remoto. COVID-19. Escola Livre de Dança da Maré.

\section{Remote dance teaching at the Escola Livre de Dança da Maré in 2020 during the COVID-19 outbreak}

\begin{abstract}
This paper attempted to reflect upon remote dance teaching experiences developed during the COVID-19 outbreak, in the city of Rio de Janeiro, in 2020, by the Escola Livre de Dança da Maré. Working with non-formal education in dance, through synchronous and asynchronous strategies, the school kept reaching out to its students the during social isolation imposed by the new coronavirus pandemic. In a context where social inequalities became even more evident for those who needed to be connected to the internet and use electronical devices to study at home, this paper reflected upon how the reality of the neighborhood of Maré did not cope with the best development of the online classes at the Escola Livre de Dança da Maré.
\end{abstract}

Keywords: Dance. Non-formal education. Remote teaching. COVID-19. Escola Livre de Dança da Maré.

${ }^{1}$ Revisão ortográfica e gramatical do artigo realizada por Caroline Coltrin Pereira. Mestranda em Linguística (UFSC). Bacharela em Linguística (UNICAMP). carolinecoltrin@gmail.com

${ }^{2}$ Mestrando em Dança pela Universidade Federal do Rio de Janeiro (UFRJ). Licenciado em Dança pela UFRJ. gabrielrflima@gmail.com

http://lattes.cnpq.br/9524284798657952 (iD https://orcid.org/0000-0003-4655-5039 


\section{Enseñanza de danza a distancia en la Escola Livre de Dança da Maré en 2020 durante el brote de COVID-19}

\section{Resumen}

Este trabajo intentó reflexionar sobre las experiencias de enseñanza de danza a distancia desarrolladas durante el brote de COVID-19, en la ciudad de Río de Janeiro, en 2020, por la Escola Livre de Dança da Maré. Trabajando con la educación no formal en danza, mediante de estrategias sincrónicas y asincrónicas, la escuela siguió llegando a sus estudiantes durante el aislamiento social impuesto por la nueva pandemia de coronavirus. En un contexto en el que las desigualdades sociales se hicieron aún más evidentes para quienes necesitaban estar conectados a internet y utilizar dispositivos electrónicos para estudiar en casa, Este artículo reflexionó sobre cómo la realidad del barrio de Maré no ha afrontado el mejor desarrollo de las clases online de la Escola Livre de Dança da Maré.

Palabras Clave: Danza. Educación no formal. Enseñanza remota. COVID-19. Escola Livre de Dança da Maré. 


\section{Carta para docentes de um outro tempo ou lembranças sobre ensino remoto}

Querida professora e querido professor,

Esta é uma carta, só que ao contrário. Ela fala de uma aula, só que ao contrário. Estamos no ano de 2020 e Alice está através do espelho - espelho esse que, nesse caso, é uma tela. Parabéns! Este é o desaniversário da sala de aula.

A escola está sem muros e já não há mais quadro negro, nem filas de cadeiras. Talvez nem haja alunos e alunas na escola. "Alice, você está aí? Alice, seu microfone está fechado"... talvez a Alice nem esteja na escola. Onde é a escola? O que era público nesse ambiente e o que a escola tornava público já não é mais dessa maneira. Ou ainda: o privado talvez seja o novo público, pois a sala de aula virou sala de casa. "Estou atrasado, estou atrasado" - mesmo com a sala de aula sendo em casa, ninguém parece chegar na hora. Humm... hora do chá. Hora do almoço. CAMPAINHA! Hora de atender a porta. Só a hora do recreio parece ser esquecida na escolarização de cada casa. Qual é o real tempo da escola no tempo da casa? Ainda que cada uma seja um caso e que em cada lugar caiba um bocado de cada coisa que cada escola traz, ainda fica a pergunta no ar: onde a escola foi parar?

Naquela escola que queríamos sem muros, hoje nem todos entram. Agora, as barreiras são outras e os muros são invisíveis. Às vezes, nem os professores entram: "Sua conexão falhou. A sala caiu." Esse espaço anulado da escola faz com que o espaço através do espelho que precisamos atravessar para chegar ao outro nos coloque ainda mais em contato conosco. As nossas telas-espelhos, que não mostram muito mais do que as nossas próprias cabeças, fazem-nos encarar horas de uma realidade recortada do que pode ser o corpo e o ensino. "CORTEM-LHE A CABEÇA!" - gritam os alunos e as alunas em desespero, pois é nada mais do que veem por horas a fio nas tentativas desesperadas de reprodução da velha escola.

Todavia, o mundo agora é outro. Nessa realidade, o conhecimento sobre as disciplinas e os textos não é suficiente. A leitura não é suficiente. O que a gente leva da escola para casa efetivamente? Procuramos o coelho branco, mas só 
encontramos o gato de Alice pulando em nossas telas e nos assustando: "Alice, seu microfone está fechado!"

O professor parece ser o único que leva a escola para dentro da casa de cada aluno e de cada aluna. A gente valoriza tanto a escola, mas do professor a gente quer só a cabeça. Como uma mensagem na garrafa ou até mesmo uma salvação - como se a escola se resumisse no que ela objetivamente ensina.

A escola agora é vista através do espelho e ninguém pensou no corredor, no calor, no zelador... muito pelo contrário: só lembraram do professor. Esqueceram da merendeira, da diferença entre quarta e quinta-feira e da cola embaixo da cadeira. O que o aluno faz com as amizades, com aquele empurrãozinho quando falta vontade e com o namoro no começo da puberdade?

A escola está cada vez mais com menos corpo e cada uma das telas parece uma ilha. Querido professor, desculpe, mas esse não é o País das Maravilhas.

\section{Da sala de dança para a sala de casa}

As aulas presenciais na Escola Livre de Dança da Maré (ELDM) ${ }^{3}$ foram interrompidas no dia 16 de março de 2020, em função da pandemia da COVID-19. Pela ELDM, passam anualmente 300 estudantes nas diversas oficinas que a Escola oferece, todas gratuitas. Esse projeto social acontece desde outubro de 2011 na favela da Nova Holanda, no Complexo de Favelas da Maré, localizado no Rio de Janeiro - ele "se constituiu como um conjunto de atividades integradas em torno do ensino da dança" (Coutinho; Soter, 2019, p.71).

A Escola é fruto da parceria entre a Instituição da Sociedade Civil Redes de Desenvolvimento da Maré e a Lia Rodrigues Companhia de Danças. A Redes da Maré, que teve seu processo de criação iniciado em 1997, é uma instituição que atua no território da Maré a partir de quatro eixos de trabalho: Arte, Cultura, Memórias e Identidades; Direito à Segurança Pública e Acesso à Justiça; Educação;

Mais sobre a Escola Livre de Dança da Maré pode ser encontrado em: <https://www.redesdamare.org.br/br/info/7/escola-livre-de-danca-da-mare-eldm> . Acesso em: 06 mar. 2021. 
e Desenvolvimento Territorial. Em 2020, essa instituição possuía mais de 40 projetos em curso, sendo a Escola Livre de Dança da Maré um deles. ${ }^{4}$ Já a Lia Rodrigues Companhia de Danças ${ }^{5}$ é uma companhia profissional com mais de 30 anos de atuação nas cenas nacional e internacional. Seu nome deve-se à Lia Rodrigues, uma coreógrafa premiada, da qual sua obra e seu método foram alvos de diversas pesquisas acadêmicas no campo das artes e da educação ${ }^{6}$. A conexão entre Lia Rodrigues e a Redes da Maré ocorreu quando, em 2004, a coreógrafa chegou ao bairro para uma residência coreográfica (Pavlova, 2015, p.14) e lá estabeleceu a sede de ensaios de sua companhia. Em parceria com a Redes da Maré, inaugurou em 2009 o Centro de Artes da Maré, um local para as artes do lugar e da cidade, em que acontecem as atividades da Escola Livre de Dança da Maré e também onde a Lia Rodrigues Companhia de Danças trabalha diariamente (Pavlova, 2015, p.67).

A Escola Livre de Dança da Maré é um projeto que oferece aulas de dança através de ensino não-formal' ${ }^{7}$ o qual possui dois núcleos em sua concepção - o Núcleo 1, composto pelas aulas abertas da Escola, sendo elas, em 2020, balé clássico, consciência corporal, dança afro-brasileira, dança de salão e danças

${ }^{4}$ Dados sobre a Redes da Maré disponíveis em <https://www.redesdamare.org.br/br/>. Acesso em: 25 fev. 2021.

5 Mais informações sobre Lia Rodrigues e a Lia Rodrigues Companhia de Danças disponíveis em <http://www.liarodrigues.com/> Acesso em: 04 mar. 2021.

${ }^{6}$ Algumas pesquisas sobre Lia Rodrigues: "A dança expandida de Lia Rodrigues: uma experiência artística e política" (Keffer; Pavlova, 2020); "Dança e Política: Movimentos da Lia Rodrigues Companhia de Danças na Maré" (Pavlova, 2015); "Brésilianités, de la naissance de la notion à l'analyse de Folia et Pororoca, de L. Rodrigues (Pedalino, 2010); “Artista em situação pedagógica: o ensinar na prática de Lia Rodrigues” (Soter; Braga, 2017).

${ }^{7}$ A educação não-formal se distingue da educação formal (ou ensino tradicional) em termos de estrutura, da forma como é organizada e do tipo de reconhecimento e qualificações que este tipo de aprendizagem confere. Ela é, acima de tudo, um processo de aprendizagem social, centrado no educando, através de atividades que têm lugar fora do sistema de ensino formal, do qual é, muitas vezes, complementar. A educação não-formal baseia-se na motivação intrínseca do formando e é voluntária. Como sistema de aprendizagem, vem sendo prática comum - sobretudo no âmbito do trabalho comunitário; social ou juvenil; serviço voluntário; atividade de organizações não-governamentais ao nível local; e nacional e internacional, - que abrange uma larga variedade de espaços de aprendizagem. Essa perspectiva tem formatos completamente diferenciados em termos de tempo e localização, número e tipo de participantes (formandos), equipes de formação, dimensões de aprendizagem e aplicação dos seus resultados. No entanto, é importante sublinhar que, mesmo que esse tipo de educação não apresente um currículo único, ela ainda é um processo de aprendizagem estruturado, baseado na identificação de objetivos educativos, com formatos de avaliação efetivos e atividades preparadas e implementadas por educadores revestidos da intenção de ensinar. É, portanto, neste sentido, que a educação não-formal distingue-se mais fortemente da educação informal. Em Dança, podemos tomar como exemplo desta categoria de educação as Academias de Ballet, as ONGs, os Grupos e Coletivos de Dança, correlatos e afins. (Assis; Rocha, 2017, p.11) 
urbanas; e o Núcleo 2, isto é, o Núcleo de Formação Intensiva em Dança, que teve suas atividades iniciadas em 2012, logo após a abertura da ELDM, em outubro de 2011 (Ribeiro, 2014, p.51).

Desse modo, este trabalho analisará as atividades do Núcleo 2 que ocorreram em 2020, durante o período de isolamento social devido à pandemia da COVID198. Sobre esse Núcleo, é possível afirmar que ele

contempla jovens de 14 a 25 anos, selecionadas/os via audição para desenvolverem um trabalho de formação técnica em dança contemporânea em contato estreito, por tempo indeterminado, com a Lia Rodrigues Companhia de Danças. As atividades do Núcleo 2 foram iniciadas em 2012 e mais de sessenta jovens já passaram por este projeto de 2012 a 2019. As aulas do Núcleo 2 acontecem de segunda a sextafeira, de $14 \mathrm{~h}$ às $17 \mathrm{~h} 30$, e as/os alunas/os recebem uma bolsa auxílio para custear despesas básicas de transporte e alimentação. O intuito do Núcleo 2 é, para além da formação técnica, contribuir na formação de cidadãos por meio da dança (Lima; Soter, 2020, p.74)

No início de 2020, ele contava com 15 jovens. A rotina de trabalho do grupo contemplava, naquele momento, aulas de dança contemporânea, de balé clássico e de inglês. Além disso, o grupo propunha encontros com uma equipe de psicólogas e estudantes de Psicologia da Universidade Estadual do Rio de Janeiro (UERJ) e conversas sobre temas que contemplam a raça, o gênero, a juventude e a segurança pública. Para além da carga habitual de trabalho, fora iniciada, em março de 2020, uma residência coreográfica com a coreógrafa Cristina Moura, que durou duas semanas de modo presencial. Com o início do isolamento social, todas as atividades presenciais foram suspensas.

A situação do isolamento social, em contraposição à necessidade da continuidade de trabalhos, foi uma realidade compartilhada por todas as instituições de ensino do mundo, nas quais o isolamento social impediu a ida à escola. Todavia, a forma de dar continuidade às atividades educacionais foi muito diferente em cada contexto. A Escola Livre de Dança da Maré nunca havia passado por uma experiência como a imposta pela pandemia da COVID-19, a qual foi enfrentada com dificuldade, pois a instituição não possuía tecnologia ou expertise 
para a execução de um trabalho remoto de dança. Desse modo, como havia a necessidade e o desejo de manter a escola viva, institucionalmente e dentro de cada aluna e de cada aluno, estratégias criativas precisaram ser criadas.

\section{Estratégias do ensino remoto de dança}

Larrosa (2018, p.27) entende que a escola é para o professor o que a padaria é para o padeiro e o que o sapato é para o sapateiro. A escola é para o professor, segundo Larrosa (2018, p. 27), "o lugar onde ele exerce seu ofício, onde mostra suas habilidades e onde estão tanto suas matérias-primas quanto suas ferramentas ou seus artefatos". Enquanto educador, durante a pandemia de COVID-19, vi-me destituído do espaço da escola - distante do que Larrosa (2018) chama de "ferramentas e artefatos" (p.27) e equipado apenas com o que tinha no corpo e em casa. Do mesmo modo, estavam muitas e muitos colegas docentes.

Para a dança, as especificidades das condições de trabalho são ainda muito maiores do que para outras áreas do conhecimento, isto é, há a necessidade do chão adequado, do espaço, da presença do outro e de outras ferramentas. Se entrarmos nas questões técnicas para o ensino remoto de dança, a lista das especificidades é enorme: o delay entre som e imagem no vídeo, a câmera que não capta o todo o corpo das pessoas, a dificuldade no uso de música e também a dificuldade de se editar vídeos caso as aulas não possam ser assistidas ao vivo (quando um professor de dança imaginou que a sua aula talvez não fosse assistida ao vivo?). O ensino de arte não é baseado apenas em conteúdos e uma aula de dança é da ordem do acontecimento e do encontro. Como ensinar algo que é da ordem do acontecimento e do encontro quando o acontecimento nem sempre pode ocorrer porque não há conexão de internet? Ou quando o encontro é via tela de computador, estando cada pessoa em sua casa? Isso quando há a possibilidade de se utilizar um computador.

Desse modo, o início da pandemia da COVID-19 foi um grande choque para as/os trabalhadoras/es da Educação. "Pegas de surpresa e sem infraestrutura nem experiência com o ensino remoto, escolas no Brasil e no mundo foram, gradualmente, desenvolvendo estratégias de educação à distância” (Redes da 
Maré, 2021) - foi exatamente assim que aconteceu na ELDM. Esse era um momento em que o Estado do Rio de Janeiro havia acabado de entrar em isolamento social, portanto suas atividades não essenciais estavam proibidas pelo decreto no 46.970, de 13 de março de 2020. O decreto, em seu artigo 4o, dispôs que:

De forma excepcional, com o único objetivo de resguardar o interesse da coletividade na prevenção do contágio e no combate da propagação do coronavírus, (COVID-19), determino a suspensão, pelo prazo de 15 (quinze) dias, das seguintes atividades: I - realização de eventos e atividades com a presença de público, ainda que previamente autorizadas, que envolvem aglomeração de pessoas, tais como: eventos desportivos, shows, feiras, eventos científicos, comícios, passeatas e afins; II - atividades coletivas de cinema, teatro e afins.

Com essa medida, foram suspensas as atividades presenciais do Centro de Artes da Maré e da Escola Livre de Dança da Maré. Quando foi finalizado o artigo, em junho de 2021, mais de um ano após o início da pandemia da COVID-19, as atividades do CAM seguiam suspensas de forma presencial.

Enquanto formas de ensino na ELDM para o Núcleo de Formação Intensiva em Dança, foram adotadas estratégias síncronas e assíncronas de trabalho para que as atividades da escola não parassem - essa ideia foi nova para o ensino remoto de dança na ELDM. Para elucidar, Santos, Matos e Eça (2020, p. 64-66) definem o que podem ser ferramentas síncronas e assíncronas para um ensino remoto:

As ferramentas síncronas são aquelas em que a participação entre os estudantes e professores ocorre em tempo real, isto é, a interação online, àquelas conectadas no tempo e espaço virtual. São exemplos de ferramentas síncronas: a. Webconferência (podem ser feita no formato de audioconferência, videoconferência ou teleconferência) b. Chats (sala de bate papo). [...] As ferramentas de aprendizagem assíncronas são aquelas que ocorrem em offline, ou seja, desconectadas de tempo e espaço. A principal diferença entre os dois tipos de ferramentas é que as assíncronas se tornam mais flexíveis para os estudos em EaD online. São exemplos de ferramentas assíncronas: a) Fórum: esta ferramenta também é conhecida como listas de discussão e se constitui uma das ferramentas mais importantes na $\mathrm{EaD}$ online, pois permite interação e colaboração em reflexão sobre temáticas pertinentes ao curso. Assim como, debates escolhidos pelos próprios estudantes. É uma ferramenta interessante para tirar dúvidas, compartilhar novas informações e interagir na busca de novos conhecimentos. b) E-mail: as correspondências eletrônicas são ferramentas de comunicação muito 


\begin{abstract}
presente em nossas vidas e na EaD online são bastantes importante para transferir arquivos, tirar dúvidas esse comunicar com os colegas. c) Blog: a organização do blog se assemelha bastante com um fórum. Este conteúdo pode ser produzido através de vídeos, áudios, textos, links, sugestões de estudos, etc. d) Questionário: é muito usado na EaD online para aplicação de avaliação, pois favorece a elaboração de perguntas em diferentes formatos e facilita à correção automática. e) Tarefa: é a ferramenta, comumente, usada pelos estudantes para enviar trabalho ou arquivo de forma online f) Wiki: ferramenta que permite o trabalho colaborativo de produção textual online entre os estudantes. g) Diário: é um lugar de interação direta entre estudante e mediador. Local de reflexão restrita ao estudante e mediador (Santos; Matos; Eça, 2020, p.6466).
\end{abstract}

Após uma reflexão inicial e consulta às possibilidades tecnológicas das/os alunas/os, a equipe pedagógica da ELDM criou uma primeira proposta assíncrona de trabalho. O início das atividades a distância levou em conta questões como a falta de estrutura tecnológica do grupo para a realização de aulas síncronas, já que de 15 estudantes, apenas 8, em março de 2020, possuíam computador em casa Esse dado significava que, para metade do grupo, qualquer atividade teria que acontecer a partir da tela de um celular, dispositivo pelo qual se deu toda e qualquer comunicação durante o período de isolamento social com esse grupo. A partir deste dado, a primeira proposta consistiu em uma estratégia assíncrona para o Núcleo de Formação Intensiva em Dança. Para esta proposição, fora construída uma lista de referências de materiais de dança para que as/os alunas/os pudessem estudar em suas casas, a partir do tempo disponível para cada um/a. Nas palavras de Gadotti (2005), nós só podemos conhecer realmente o que é construído de modo autônomo. Segundo ele, "Frente à disseminação e à generalização da informação, é necessário que a escola e o professor, a professora, façam uma seleção crítica da informação, pois há muito lixo e propaganda enganosa sendo veiculados" (Gadotti, 2005, p.3). Assim, a escolha, frente à vontade de se continuar com o trabalho e à falta de recursos adequados, focou na autonomia de cada estudante e contou com o suporte da equipe pedagógica da escola, que direcionou o aprendizado.

Na lista criada e disponibilizada para as/os alunas/os, foram adicionados 
vídeos de espetáculos de dança, documentários, entrevistas com artistas, textos, aulas de dança gravadas pelas professoras do grupo e outros materiais previamente selecionados e colocados à disposição das/os alunas/os para que elas/es pudessem, de acordo com o tempo disponível naquele momento, decidir quais caminhos seguir, sabendo que podiam recorrer, a qualquer momento, à equipe pedagógica da escola. Nesse momento, o uso de aplicativos de mensagens foi o veículo escolhido para a comunicação e conexão entre o grupo, as professoras/es e a coordenação da escola. A realização desta proposta assíncrona deu o tempo necessário para que a ELDM entendesse como lidar com suas atividades e as demandas trazidas pela pandemia. A independência dos jovens foi utilizada como ferramenta pedagógica num momento de muitas incertezas sobre a duração do isolamento social e sobre a pandemia.

Gadotti (2005, p.4), ao pensar sobre a cidade e a educação, diz que a "casa tornou-se a cidade onde há de tudo: o teatro, home theater, o cinema, a livraria, o banco... não precisamos mais sair de casa, nem crianças, nem adultos." Segundo o autor, a casa teria se tornado um lugar independente da cidade. Esse texto de 2005 apresenta um pensamento sobre uma cidade grande como São Paulo - em 2021, esse pensamento ainda é correto, mas com recortes muito específicos que não se aplicam em todas as cidades.

O Censo Populacional da Maré (Redes da Maré, 2018) verificou a presença de computadores em $42,4 \%$ dos domicílios do bairro, nos quais a internet estava presente em apenas 36,7\%. Segundo dados do Censo Populacional da Maré (Redes da Maré, 2018, p. 97), "trata-se de uma proporção bem abaixo da estimada para a Região Metropolitana do Rio de Janeiro em 2013”, que, segundo dados da Pesquisa Nacional por Amostra de Domicilios (PNAD) do IBGE, estimou a presença de computador em 62,2\% dos domicílios. Ainda segundo o Censo, "na Região Metropolitana do Rio de Janeiro, porém, havia computador com acesso à internet em 56,1\% dos domicílios, segundo a PNAD de 2013” (Redes da Maré, 2018, p. 95). Para se ter uma ideia da dimensão do Complexo de Favelas da Maré, ele é composto por 16 favelas distintas e possui 47.758 domicílios, que abrigam mais de 139.000 habitantes - isso faz com que o bairro seja mais populoso do que $96 \%$ dos municípios brasileiros (Redes da Maré, 2018). Todavia, mesmo sendo um bairro de 
proporções municipais, não é em todas as casas que se há as facilidades presentes na cidade, uma vez que nem computador ou internet boa parte dessas casas possuem. Diferente do que afirma Gadotti (2005) ao pensar sobre grandes cidades, não há de tudo em toda casa.

Uma pesquisa que abordou a educação de meninas e a COVID-19 na Maré (Redes da Maré, 2021), da qual participou um grupo de 1.009 moradoras do território a partir dos 6 anos de idade, matriculadas em escolas de ensino regular ou em projetos educacionais na região, mostrou que 34,7\% das entrevistadas não possuíam internet em casa e que 66,5\% conseguiam manter uma rotina de estudos em suas residências. É sabido que a qualidade da internet na Maré e em outros territórios de favela não é boa o suficiente ${ }^{10}$ e essa situação foi agravada durante o período de isolamento social na cidade do Rio de Janeiro, em que o roubo de cabos de telefonia fez com que muitas áreas ficassem sem conexão11.

A internet (e a falta dela), somada às questões trazidas pelo isolamento social no que diz respeito ao ensino de dança, tornaram as atividades da ELDM bastante desafiadoras. Segundo a professora de balé clássico do Núcleo de Formação Intensiva em Dança Sylvia Barreto, "a dança requer presença, por isso a aula à distância não é fácil. [...] Falta espaço em casa, o chão não é adequado, mas estamos tentando."12 Essa fala ilustra bem a dificuldade que as/os professores enfrentaram no trabalho de ensino remoto, pois a dança exige mais do que somente a presença do corpo diante de uma tela. É preciso espaço adequado, troca e contato.

Ademais, como estratégia assíncrona de ensino, foi dada continuidade à residência com a coreógrafa Cristina Moura, que pode ser observada na Figura 1,

${ }^{10}$ Mais informações podem ser lidas na matéria Pandemia e internet: mais um dos desafios dos moradores da Maré, Disponível em: <https://mareonline.com.br/pandemia-e-internet-mais-um-dos-desafios-dosmoradores-da-mare/>. Acesso em: 28 fev. 2021.

${ }^{11}$ A situação de roubo de cabos em diversas áreas da cidade do Rio de Janeiro foi um agravador da situação de internet durante a pandemia de COVID-19, como relata a matéria Moradores denunciam furtos de cabos de energia e telefonia em diversas regiões do Rio, Disponível em: <https://g1.globo.com/rj/rio-dejaneiro/noticia/2020/07/21/moradores-denunciam-furtos-de-cabos-de-energia-e-telefonia-em-diversasregioes-do-rio.ghtml>. Acesso em: 28 fev. 2021.

12 Depoimento retirado da matéria Dois para cá, dois para lá, a dança não pode parar. Disponível em: <https://mareonline.com.br/dois-para-ca-dois-para-la-a-danca-nao-pode-parar/>. Acesso em: 28 fev. 2021 
num momento anterior ao início da pandemia. Mediante a inviabilidade dos encontros do grupo no Centro de Artes da Maré13, uma vez que as atividades seguiram suspensas pelo decreto estadual no 46.970, de 13 de março de 2020, a coreógrafa começou a enviar tarefas para as/os estudantes via aplicativos de comunicação. As tarefas consistiam em desdobramentos do processo criativo iniciado presencialmente: assistir a vídeos de dança e gravar um solo de dança reproduzindo uma imagem desses vídeos; regravar o solo com uma roupa de gala; gravar um vídeo estático de uma parede da casa de cada um/a falando um texto escrito pela própria pessoa relacionado ao solo criado; e tirar foto das mãos da pessoa mais nova e daquela mais velha da casa/rua/vizinhança. Essas, entre outras tarefas, compuseram um banco de imagens do processo de criação, o qual foi trabalhado por Cristina Moura no produto final da residência, que ganhou forma de vídeo e não pôde ser apresentado presencialmente, como havia sido inicialmente planejado. Esse trabalho foi chamado de A Escrita é o Corpo e contou com a participação de 14 jovens do Núcleo de Formação Intensiva em Dança ${ }^{14}$. Em paralelo à realização das tarefas, foram realizados encontros síncronos em plataformas de videoconferência para conversas sobre o andamento do processo remoto de criação coreográfica. O processo, que presencialmente tinha previsão de durar um mês, com quatro encontros por semana, estendeu-se, de forma remota e com atividades assíncronas, por pelo menos cinco meses.

O trabalho executado com a coreógrafa Cristina Moura também focou na autonomia das/os jovens e nas relações que eram agora estabelecidas com os espaços em que elas/es estavam: suas casas. A coreógrafa utilizou estímulos que conectassem as/os jovens aos seus espaços e que, ao mesmo tempo, os

${ }^{13}$ As atividades artísticas e educativas presenciais foram suspensas no Centro de Artes da Maré em 2020 e o espaço virou um dos principais pontos de articulação da campanha de atendimento humanitário Maré Diz NÃO ao Coronavírus. Organizada pela Redes da Maré entre março e outubro de 2020, a campanha teve como objetivos "(i) Segurança alimentar e nutricional; (ii) Atendimento às populações em situação de rua; (iii) Geração de trabalho e renda; (iv) Acesso a direitos, cuidados e prevenção em saúde; (v) Produção e difusão de informações e conteúdos seguros; (vi) Apoio a artistas, produtores e grupos culturais locais". O CAM deu lugar ao recebimento de cestas básicas, que chegavam no espaço para serem entregues para as famílias da Maré de porta em porta, atendendo, ao fim da campanha, 17.648 famílias. Informações disponíveis em: <https://www.redesdamare.org.br/media/downloads/arquivos/RdM Relatorio campanha.pdf $>$. Acesso em: 01 mar. 2021.

${ }^{14}$ Trechos e depoimentos sobre o processo da residência coreográfica podem ser assistidos nos links a seguir: <https://vimeo.com/407813049>, <https://vimeo.com/484077127> . O vídeo de A Escrita é o Corpo pode ser conferido no YouTube da Redes da Maré: <https://www.youtube.com/channel/UCQHNqSAxol9a2xedHIhhusA>. Acesso em: 15 jun. 2021. 
colocassem em relação, já que a presença física no mesmo local não seria possível para a finalização da residência coreográfica.

Figura 1 - Coreógrafa Cristina Moura e o Núcleo 2 no CAM, mar. 2020

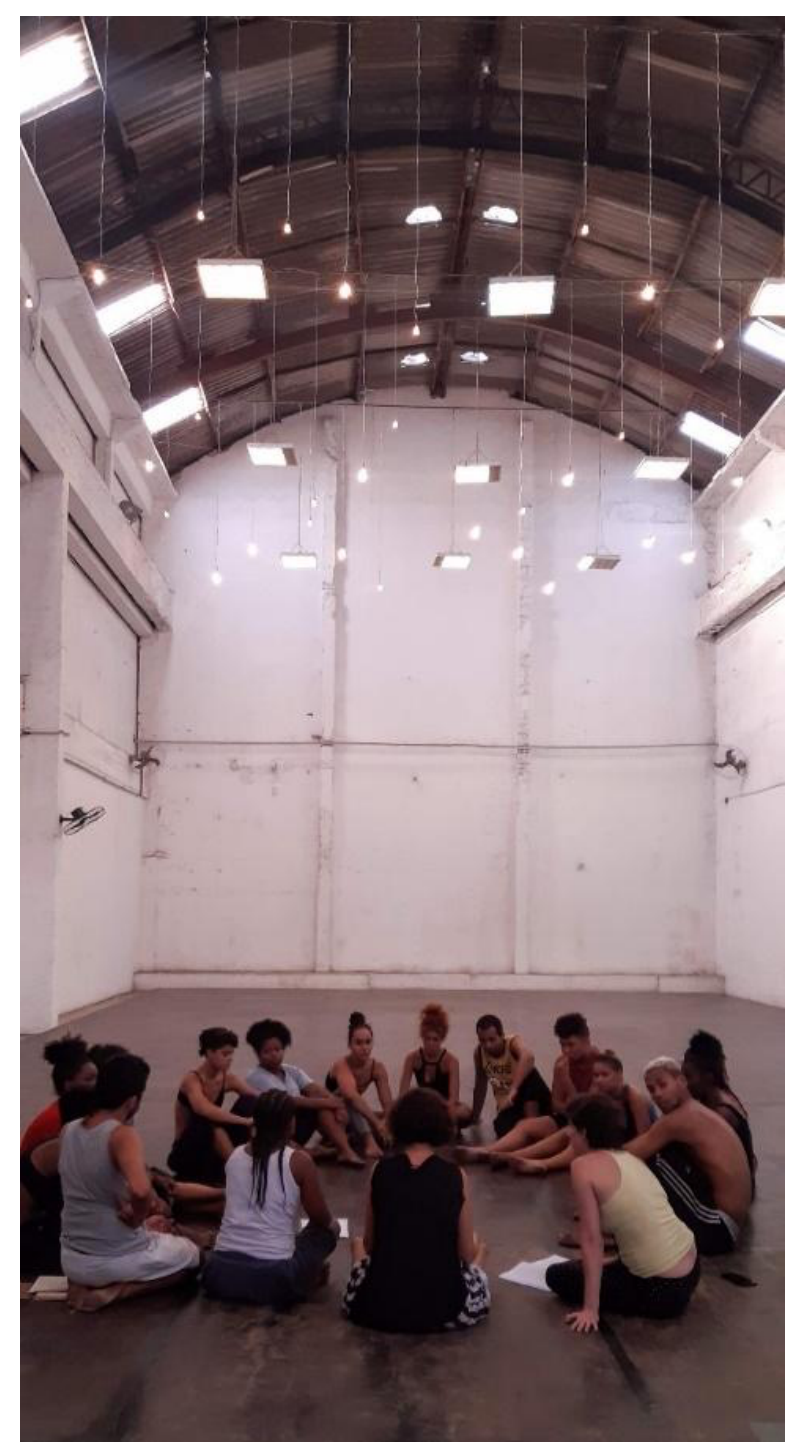

Fonte: Elaboração própria

Estratégias síncronas de ensino também foram adotadas quando houve avanço da pandemia ao longo de 2020, no momento em que se compreendeu que o isolamento social não era temporário, como foi cogitado de início. Porém, com o transporte da sala de dança para a sala de casa, muitas questões surgiram para o ensino de dança. Larrosa e Rechia $(2018$, p.73) refletiram sobre a sala de aula e seu efeito no corpo do professor: 


\begin{abstract}
Eu acredito que na sala de aula não se pode estar "como em casa", que tanto os alunos quanto o professor tem que se sentirem um pouco incômodos, um pouco estranhos, um pouco deslocados. É preciso fazer com que a sala de aula seja sentida como um espaço separado, distinto, com suas próprias normas e rituais, um espaço exigente. Porque somente assim a aula se transforma em um espaço generoso, um espaço que, por sua própria estrutura, te coloca sobre o que és, te faz ser melhor (ser mais cuidadoso, mais atento) do que és. Ademais, da mesma maneira que as ferramentas (e a oficina) do carpinteiro configuram o corpo do carpinteiro (suas mãos, seus movimentos, seus gestos), eu acredito que a sala de aula configura o corpo do professor, não apenas sua mente. Tenho a sensação de que o corpo do professor (meu próprio corpo como professor) é um efeito da sala de aula (Larrosa; Rechia, 2018, p.73).
\end{abstract}

Considerando os ditos de Larrosa e Rechia, qual é o corpo do professor quando a sala de aula tornou-se, necessariamente, a sala de casa? E que, ao dar aula, a ideia de não estar "como em casa" é muito distante, justamente porque a casa é o ambiente de trabalho do professor e é onde o aluno se torna aluno?

As primeiras aulas síncronas a acontecerem para o Núcleo de Formação Intensiva em Dança foram as aulas de balé e dança contemporânea, seguidas pelas aulas de Inglês. As aulas de balé clássico, de formato muito característico, com uso muito específico do espaço, tiveram que ser adaptadas à realidade da casa da professora e das/os alunas/os. Cadeiras e paredes foram transformadas em barras para apoio na execução de movimentos e o uso do espaço teve de ser totalmente adaptado, pois nem sempre houve a possibilidade de deslocamento pela casa para realização de passos e atividades característicos da técnica clássica. O foco do trabalho precisou ser alterado, dando-se maior ênfase a elementos como flexibilidade e memória. No trabalho de flexibilidade, o chão foi muito utilizado, elemento necessariamente comum a todas/os as/os alunas/os. Enquanto isso, a memória torna-se item essencial numa aula em que não é possível olhar para o lado (pois se está sozinho e a única referência visual é frontal) e em que tirar dúvidas é muito mais difícil.

Para as aulas de dança contemporânea, o tempo foi uma grande questão. Antes, os encontros possuíam 3 horas de duração e ocorriam duas vezes por semana. Nesse novo formato, as aulas passaram a ter ocorrência semanal com duração de até duas horas para reduzir o tempo em frente às telas - lembrando 
que a tela, para mais da metade do grupo, era a do celular. Para essa modalidade de dança, foi importante o foco em elementos como a improvisação e a consciência corporal. Nessas atividades, cuja execução individual já acontece em aulas de dança em situações normais, foi possível que as/os alunas/os trabalhassem a partir das necessidades e possibilidades de cada um/a em termos de corpo, espaço e disponibilidade a cada aula. Assim, pode-se considerar o isolamento social na execução das atividades, sem que apenas uma importação de um modelo presencial acontecesse para as aulas remotas de dança.

Uma pesquisa da Universidade de Stanford ${ }^{15}$, nos Estados Unidos, baseada em relatos, mostra que o excesso de horas em frente a telas durante a participação em videoconferências pode ser prejudicial à saúde e causar o que o estudo chama de Fadiga do Zoom ${ }^{16}$. Dentre os fatores identificados estão: (i) cansaço visual por olhar para a tela a uma curta distância; (ii) efeito espelho (olhar para a própria imagem por um longo período); (iii) mobilidade reduzida; e (iv) comunicação não verbal excessiva (como a utilização de gestos). A pesquisa supracitada fala de reuniões em formatos convencionais, não de aulas de dança, mas podemos pensar a partir dela para considerar alguns fatores que influenciam na ocorrência dessas aulas remotas.

A pesquisa de Stanford pensa, então, nesses 4 fatores prejudiciais à saúde e causadores da Fadiga do Zoom. Traçando um paralelo, em uma aula remota de dança que se repete várias vezes, como as do Núcleo de Formação Intensiva em Dança, poderíamos ter alguns fatores que prejudicam a melhor ocorrência das aulas, em adição aos fatores que a pesquisa de Stanford já coloca. Dentre eles, estão: (i) a visualização de apenas partes do corpo de quem faz a aula ou de quem propõe o encontro devido ao que é possível ser enquadrado nas câmeras,

15 Artigo Disponível em: inglês em <https://vhil.stanford.edu/mm/2021/02/sn-zoom-fatigue.pdf> e matéria publicada em português no site UOL em <https://www.uol.com.br/vivabem/noticias/deutschewelle/2021/03/02/a-pandemia-e-a-fadiga-do-zoom.htm>

Acesso em: 05 mar. 2021.

16 "A Zoom Vídeo Communications é uma empresa americana de serviços de conferência remota com sede em San Jose, Califórnia. Ela fornece um serviço de conferência remota Zoom, que combina videoconferência, reuniões online, bate-papo e colaboração móvel. O software homônimo da Zoom está entre as soluções de reuniões remotas mais populares em muitos países." Disponível em: <https://pt.wikipedia.org/wiki/Zoom Video_Communications>. Acesso em: 06 mar. 2021. 
causando falhas na comunicação ou no entendimento das atividades propostas como um todo, bem como a correção e auxílio às/aos alunas/os por parte de quem está facilitando a aula; (ii) o delay, isto é, o atraso no processamento dos dados, que faz com que som e imagem não sejam entregues ao mesmo tempo e nem para todas as pessoas da videoconferência ao mesmo tempo; (iii) a dificuldade da comunicação verbal, uma vez que nem sempre é possível ter os microfones de todas/os as/os participantes de uma videoconferência abertos por conta da interferência que isso causa na chamada; e (iv) a instabilidade das plataformas de videoconferência e da internet, especificamente na cidade do Rio de Janeiro, que comprometem a ocorrência fluida de chamadas de vídeo, o que causa cortes durante a aula. Nesse ponto, incluo a necessidade de se desligar a própria câmera para que se possa, ao menos, ouvir quem fala, pois ter as câmeras ligadas consomem mais dados de internet e reduz a qualidade da chamada em uma conexão ruim.

A mesma pesquisa de Stanford propõe algumas soluções para a redução da Fadiga do Zoom, como exemplo, retirar a própria imagem da tela durante reuniões, evitar o uso de programas de chamada de vídeo em tela-cheia e desligar a própria câmera. Para uma aula de dança, em que não somente instruções são ouvidas, mas ações e tarefas são executadas e precisam ser vistas, principalmente por quem está facilitando o encontro, tais soluções não são tão viáveis. Numa aula de dança, é preciso ser visto e tirar dúvidas, principalmente quando se está sozinha/o em casa e sem a supervisão presencial de uma/um profissional qualificada/o ou sem alguém do lado para quem se possa olhar.

Na ELDM, para as aulas do Núcleo de Formação Intensiva em Dança, mesmo antes da publicação da pesquisa do Laboratório de Interação Humana Virtual da Universidade de Stanford, já haviam sido pensadas algumas estratégias para reduzir o que a Universidade chamou de Fadiga do Zoom. Essas estratégias foram pensadas pela escola, a fim de que houvesse melhores fluxos para a ocorrência de aulas remotas de dança, sendo elas: (i) consulta às/aos alunas/os quanto às possibilidades tecnológicas disponíveis para cada um/a; (ii) adoção de estratégias síncronas e assíncronas de ensino; (iii) redução da quantidade de encontros semanais; (iv) redução da duração de cada encontro; e (v) reformulação constante 
de atividades dentro do modelo remoto de ensino.

A adoção das estratégias para minimizar os impactos das aulas online mostraram-se eficazes, na medida do possível, mas nunca ideais. Isso se deu porque o trabalho por meio do uso de tecnologias para conexão remota é bastante excludente e tira a ideia de democratização de ensino que está no cerne das atividades da Escola Livre de Dança da Maré. Como disse a filósofa Judith Butler (Butler apud Ferreira, 2020, p.21),

a desigualdade social e econômica garantirá a discriminação do vírus. O vírus por si só não discrimina, mas nós humanos certamente o fazemos, moldados e movidos como somos pelos poderes casados do nacionalismo, do racismo, da xenofobia e do capitalismo. Parece provável que passaremos a ver no próximo ano um cenário doloroso no qual algumas criaturas humanas afirmam seu direito de viver ao custo de outras, reinscrevendo a distinção espúria entre vidas passíveis e não passíveis de luto, isto é, entre aqueles que devem ser protegidos contra a morte a qualquer custo e aqueles cujas vidas são consideradas não valerem o bastante para serem salvaguardadas contra a doença e a morte (Butler apud Ferreira, 2020, p.21).

As desigualdades que um processo como este evidencia são muito grandes. Alunas/os que não conseguem conectar-se à internetcom a qualidade necessária, a falta de espaço para participar das aulas e todas as mudanças causadas pela COVID-19 dificultaram a adesão às aulas online e a motivação não só na Escola Livre de Dança da Maré, mas nos sistemas de educação como um todo ${ }^{17}$.

\section{Considerações finais}

Longe de querer dar conta de todas as questões provenientes da ocorrência

\footnotetext{
17 Com dados de julho de 2020, "uma pesquisa do Datafolha para as fundações Lemann, Itaú Social e Imaginable Futures com pais ou responsáveis de 1.556 estudantes de escolas públicas do país concluiu que aumentou de $74 \%$ (desde maio) para $82 \%$ o índice de alunos que estavam recebendo atividades escolares em casa, seja por material impresso ou celulares, TV, rádio e computador, ou uma combinação desses meios. Mas isso ainda deixa quase 1 em cada 5 estudantes da rede pública sem ter feito atividades remotas da escola. A proporção de alunos sem acesso aos conteúdos escolares era ainda maior na região Norte (38\% contra $18 \%$ do resto do país) e em casas que concentram três ou mais estudantes. Além disso, a falta de motivação dos jovens com as atividades remotas passou de 46\% em maio para 51\% em julho. Mas o dado mais preocupante da pesquisa é de que os pais de mais de um terço dos estudantes dizem que seus filhos consideram muito difícil a rotina de estudos remotos e correm o risco de abandonar a escola por causa disso." Disponível em: <https://www.bbc.com/portuguese/brasil-54380828>. Acesso em: 15 jun. 2021.
} 
de aulas remotas de dança, este artigo visou o registro das propostas adotadas pela Escola Livre de Dança da Maré ao contextualizar as práticas da Escola e marcar um acontecimento específico num tempo tão singular. Acredito que as respostas não sejam fechadas e que as perguntas não sejam finitas, já que estamos num momento que já se prolongou por mais de um ano e que trouxe tantas incertezas e constantes questionamentos para a educação.

Os aprendizados vêm acontecendo a cada dia e ainda não parece ser possível traçar um panorama de conclusões concretas para além do relato de práticas. A pandemia da COVID-19 alterou em muito a forma de se trabalhar com educação em todo o mundo - especificamente, para o ensino de dança, as consequências foram enormes. Não só as/os professoras/es viram-se destituídas/os de seus espaços de trabalho e do contato interpessoal, intrínsecos ao trabalho da dança, mas também as questões da pandemia trouxeram à luz muitas facetas das desigualdades sociais. As diferenças nos colocam em lugares muito diferentes no que diz respeito às possibilidades de acesso ao mundo nos mais diferentes níveis e isso não pode ser desconsiderado quando se trata da concepção de estratégias pedagógicas que se querem plurais e abrangentes.

\section{Referências}

ASSIS, Thiago Santos de; ROCHA, Lucas Valentim. Referências conceituais para uma pedagogia da dança. Salvador, UFBA: 2017. Disponível em: https://repositorio.ufba.br/ri/bitstream/ri/26163/1/eBook Referencias Conceituais para uma Pedagogia da Danca-Licenciatura em Danca UFBA.pdf. Acesso em: 26 ago. 2019.

Coutinho, Marina Henriques; Soter, Silvia. Teatro e dança no Centro de Artes da Maré - ações de contra-mundo. Urdimento, Florianópolis, v.1, n.34, p.60-76, mar./abr. 2019. Disponível em:

https://www.revistas.udesc.br/index.php/urdimento/article/view/141457310134201 9060/9954. Acesso em: 30 de mar. 2021.

GADOTTI, Moacir. A Questão Da Educação Formal/Não-Formal. INSTITUT INTERNATIONAL DES DROITS DE L'ENFANT (IDE). Droit à l'éducation: solution à tous les problèmes ou problème sans solution? Sion (Suisse), 18 au 22 octobre, 2005. Disponível em:

https://aedmoodle.ufpa.br/pluginfile.php/305950/mod resource/content/1/Educa 
cao Formal Nao Formal 2005.pdf. Acesso em: 25 fev. 2021.

ESCOLA LIVRE DE DANÇA DA MARÉ. Progress Report. October 2020. Rio de Janeiro, 2020.

Ferreira, Alvaro. A cidade, a desigualdade e a pandemia. GeoPUC - Revista da Pós-Graduação em Geografia da PUC-Rio, Rio de Janeiro, v. 13, n. 24, p.12-24, jan.jul. 2020. Disponível em: http://geopuc.geo.puc-rio.br/media/v13n24a1\%20\%20Ferreira,\%20A.pdf. Acesso em: 20 mai. 2021.

KIFFER, Ana; PAVLOVA, Adriana. A dança expandida de Lia Rodrigues: uma experiência artística e política na favela Maré. Repertório. Salvador, ano 23, n. 35, p. 185-207, 2020.2. Disponível em:

https://rigs.ufba.br/index.php/revteatro/article/viewFile/38561/23972. Acesso em: 18 mai. 2021.

LARROSA, Jorge. A materialidade da escola. In.: LARROSA, Jorge . Esperando não se sabe o quê: sobre o ofício de professor. Belo Horizonte: Autêntica, 2018.

LARROSA, Jorge. RECHIA, Karen. P de professor. São Carlos: Pedro \& João Editores, 2018.

LIMA, Gabriel Ramon Ferreira; SOTER, Silvia. Construção de sujeitos corporais e práticas antirracistas na Escola Livre de Dança da Maré. Revista Artes de Educar, Rio de Janeiro, v. 6, n. 1, p.72-91, 2020. Disponível em: https://www.epublicacoes.uerj.br/index.php/riae/article/view/45780. Acesso em: 06 mar. 2021.

PAVLOVA, Adriana. Dança e Política: Movimentos da Lia Rodrigues Companhia de Danças na Maré. Dissertação (mestrado) - UFRJ / Escola de Comunicação / Programa de Pós-Graduação em Artes da Cena, 2015.

PEDALINO, Carolina. Brésilianités, de la naissance de la notion à l'analyse de Folia et Pororoca, de L. Rodrigues. Dissertação (mestrado) - Université Paris VIII SaintDenis U F R Arts, Esthétique et Philosophie MASTER Arts, mention Musique, Spécialité: Danse. 2010.

REDES DA MARÉ (org.). Censo Populacional da Maré. Rio de Janeiro: Redes da Maré, 2018. Disponível em:

https://www.redesdamare.org.br/media/downloads/arquivos/CensoMare WEB 0 4MAI.pdf. Acesso em: 30 mar. 2021.

REDES DA MARÉ (org.). Educação de meninas e COVID-19 no Conjunto de Favelas da Maré. Rio de Janeiro: Redes da Maré, 2021. Disponível em:

https://www.redesdamare.org.br/media/downloads/arquivos/pesq covid mare P ORT web60369a328ca93.pdf. Acesso em: 15 de abr. 2021

RIBEIRO, Isabella Porto. O lugar do encontro: o Centro de Artes da Maré e a trajetória de jovens na Nova Holanda. 2014. 127f. Dissertação (Mestrado em Comunicação e Cultura em Periferias Urbanas) - Universidade do Estado do Rio de 
Janeiro, Duque de Caxias, RJ, 2014.

RIO DE JANEIRO (Estado). Decreto no 46.970, de 13 de março de 2020. Disponível em: $\quad$ https://pge.rj.gov.br/comum/code/MostrarArquivo.php?C=MTAyMjE\%2C Acesso em: 03 mar. 2021.

SANTOS, Josué Leite dos; MATOS; Flávio Barreto de; EÇA, Antoniclebio Cavalcante. Tecnologias do ensino a distância. Salvador: UFBA, Escola de Teatro; Superintendência de Educação a Distância, 2020.

SOTER, Silvia; BRAGA, Paola Secchin. Artista em situação pedagógica: o ensinar na prática de Lia Rodrigues. Conceição / Conception, Campinas, SP, v. 7, n. 1, p.49-68, jan./jun. 2018. Disponível em:

https://periodicos.sbu.unicamp.br/ojs/index.php/conce/article/view/8650934/0.

Acesso em: 06 mar. 2021.

Recebido em: 15/06/2021

Aprovado em: 30/09/2021 